\title{
MOLDURAS PARA FRAGMENTOS DA HISTÓRIA DO SÉCULO XX: QUADROS DE FORMATURAS E MEMÓRIAS ESCOLARES DE COLÉGIOS CATÓLICOS BRASILEIROS NO SÉCULO XX ${ }^{1}$
}

\author{
MARCOS PARA FRAGMENTOS DE LA HISTORIA DEL SIGLO XX: \\ CUADROS DE GRADUACIÓN Y RECUERDOS ESCOLARES DE LAS ESCUELAS \\ CATÓLICAS BRASILEÑAS EN EL SIGLO XX
}

\begin{abstract}
FRAMES FOR FRAGMENTS FROM HISTORY OF THE 2OTH CENTURY: PICTURES OF GRADUATIONS AND SCHOOL MEMORIES OF BRAZILIAN CATHOLIC COLLEGES IN THE 20TH CENTURY
\end{abstract}

RESUMO: A trajetória dos sujeitos escolares está impregnada por diversidades de rituais; estes progressivamente sofreram alterações nos significados e momentos de realização, contudo, preservaram riquezas de simbolismos, profusão de sentidos e produção de bens materiais e imateriais, sendo capazes de evocar variedades de sentimentos e revolver as memórias. Dentre os rituais escolares a formatura destaca-se: ainda que tenha sofrido modificações resguarda, na contemporaneidade, conexões com os significados e simbolismos herdados das solenidades de séculos anteriores, especialmente no século XX. Estudo dos quadros de formatura, em particular, os existentes em colégios católicos brasileiros, possibilitam apreender, além da cultura escolar e as memórias inscritas pelos estudantes nesses documentos, a configuração do contexto sociocultural e histórico, e identificar a teia social na qual os colégios se imiscuíam. Analisamos 26 quadros de formaturas produzidos entre as décadas de 1930 a 1970, para celebrar a colação de grau em diferentes cursos em dois colégios confessionais católicos brasileiros dedicados exclusivamente à escolarização feminina. Para compreensão destas fontes históricas se utilizou referencial da História Cultural.

PALAVRAS-CHAVES: Memórias. Cultura escolar. Quadros de formatura. Colégios católicos. Século XX.

RESUMEN: La trayectoria de los sujetos escolares en las escuelas está impregnada de diversos rituales, estos han ido sufriendo progresivamente cambios en los significados y momentos de realización, sin embargo han conservado riquezas de simbolismo, profusión de significados y producción de bienes materiales e inmateriales, pudiendo evocar variedades de sentimientos y revolver memorias. Entre los rituales de graduación escolar se destaca: si

${ }^{1}$ A ideia original para este artigo foi apresentada no formato de Comunicação Oral no XIII CIHELA (Congresso Iberoamericano de História da Educação) - 2018, Montevideo/Uruguai, com o título Emoldurando Histórias e Memórias: quadros de formaturas nos colégios católicos brasileiros no Século XX. A partir das reflexões e escritas originais se desdobraram análises historiográficas sob outras perspectivas e mais aprofundadas sobre a cultura escolar de instituições escolares confessionais católicas durante século XX.

${ }^{2}$ Universidade Federal do Paraná (UFPR), Curitiba - PR - Brasil. Docente do Departamento de Teoria e Fundamentos da Educação (DTFE). Doutorado em Educação (UFC). ORCID: https://orcid.org/0000-0002-2340015X. E-mail: samara.mendes@ig.com.br 
bien ha sufrido modificaciones, en la época contemporánea, las conexiones con los significados y simbolismos heredados de las solemnidades de siglos anteriores, especialmente en el siglo XX. Estudiar los cuadros de graduación, en particular, los existentes en las escuelas católicas brasileñas, conocer, además de la cultura escolar y las memorias inscritas por los estudiantes en estos documentos, la configuración del contexto sociocultural e histórico, e identificar la red social en donde se ubican las escuelas. Analizamos 26 fotografias de graduación producidas entre las décadas de 1930 y 1970, para celebrar la graduación en diferentes cursos en dos escuelas confesionales católicas brasileñas dedicadas exclusivamente a la escolarización femenina. Para comprender estas fuentes históricas, se utilizó una referencia de Historia Cultural.

PALABRAS CLAVE: Memorias. Cultura escolar. Tableros de graduación. Escuelas católicas. Siglo 20.

ABSTRACT: The trajectory of school subjects is impregnated by diversities of rituals, these have progressively undergone changes in meanings and moments of accomplishment, however they have preserved riches of symbolism, profusion of meanings and production of material and immaterial goods, being able to evoke varieties of feelings and revolving memories. Among the school graduation rituals, it stands out, although it has undergone modifications, in contemporary times, connections with the meanings and symbolisms inherited from the solemnities of previous centuries, especially in the 20th century. Study of graduation boards, especially, those existing in Brazilian Catholic schools, learn, in addition to the school culture and the memories inscribed by students in these documents, the configuration of the socio-cultural and historical, and to identify the social configuration in which the schools intertwined. We analyzed 26 graduation pictures produced between the 1930s and 1970s, to celebrate the graduation in different courses in two Brazilian Catholic confessional schools dedicated exclusively to female schooling. To understand these historical sources, a reference of Cultural History was used.

KEYWORDS: Memories. School culture. Pictures of graduations. Catholic colleges. 20th century.

\section{Introdução}

A trajetória dos sujeitos escolares está impregnada por uma diversidade de rituais; estes progressivamente sofreram alterações nos significados e momentos de realização, contudo, preservaram riquezas de simbolismos, profusão de sentidos e produção de bens materiais e imateriais, sendo capazes de evocar e engendrar em todos aqueles que o vivenciaram ou mesmo no contato com "relíquias" variedades de sentimentos e revolver as memórias.

O espaço escolar é produtor de cultura(s) vivaz(es), a qual é (retro)alimentada cotidianamente por e através dos sujeitos sociais imersos e inseridos nestes, engendrando 
múltiplos e diferentes aspectos da cultura escolar, a qual pode ser expressa tanto em práticas e saberes (imaterialidade) quanto em objetos, mobiliários, edificações, etc. (materialidade) $)^{3}$

Dentre os rituais escolares que preenchem e atribuem significados ao cotidiano escolar, a formatura merece destaque, pois, ainda que tenha passado por modificações, resguarda, na contemporaneidade, conexões intrínsecas com os significados e simbolismos herdados das solenidades executadas nos séculos anteriores, especialmente no século XX.

Uma formatura é um importante momento no funcionamento das instituições escolares, destacada referência por comprovar os atos pedagógicos de sucesso processados em seu interior. Ela é o momento final de um processo de formação, significando uma graduação, um avanço reconhecido publicamente na escala de escolaridade, que diferencia os que a obtiveram das demais pessoas e que, no caso de cursos de formação profissional, marca uma prerrogativa de trabalho. [...]

Diversos elementos compõem a ritualidade da conclusão de curso, articulados a status social, condições econômicas das famílias e importância da escola em que o curso foi realizado e do título obtido. São objetos e relações variadas: anéis, solenidades festivas em auditórios com convidados, discursos (CUNHA, 2002; NASCIMENTO, DANIEL, 2002), paraninfos, bailes, missas de ação de graças, roupas especiais - smooking, toga e aparatos e símbolos que compõem o ato de conclusão de um curso e sua comemoração ritual (WERLE, 2005, p. 03-04).

Importante ressaltar que o republicanismo no Brasil se utilizou à exaustão - desde os primórdios da implementação do regime, e ainda o faz - dos ritos escolares para exaltar as conquistas do novo regime. Assim, transformar conquistas escolares em eventos públicos tornou-se estratégia singular e, com repercussões incomensuráveis, para fomentar a posição dos grupos dirigentes, além de prática social profícua, pois desperta em todos os cidadãos o desejo de conquistar a ascensão social, uma posição social mais elevada, e demonstra essa possibilidade através da dedicação aos estudos.

Lembramos que estamos a abordar e analisar a formatura na perspectiva de um rito de passagem integrante do processo escolar formal e enquanto um ritual tal qual foi instituído e reconhecido pela sociedade brasileira, demarcador da terminalidade de fase da escolarização formal e, portanto, símbolo de "conquista" de determinada ascensão social-cultural. Posto que o sujeito que "se forma" ou a quem é "autorizado participar do rito da formatura pela instituição escolar", em conformidade com a normativa social brasileira, é porque obteve os

\footnotetext{
${ }^{3}$ Para embasar a concepção de cultura escolar adotada neste texto utilizamos a percepção de Dominique Julia apresentada no texto A cultura escolar como objeto histórico (Revista Brasileira de História da Educação, $\mathrm{n}^{\circ} 1$, jan/jun 2001, p.09-43, tradução Gizele de Souza); enquanto para fundamentar a concepção de cultura escolar material apropriamo-nos da definição elaborada nos trabalhos publicados por Rosa Fátima de Souza, especialmente no texto História da cultura material escolar: um balanço inicial (BENCOSTA, 2007).
} 
conhecimentos acadêmicos-científicos pertinentes, autorizando-o a estar naquele lugar, lugar social de formando, aquele que é reconhecido publicamente como detentor de saberes.

E, ainda que tenha passado por alterações no formato ao longo do último século, e tenha adquirido variações entre as diferentes regiões e cidades brasileiras, os significados e simbolismos sociais da formatura mantiveram-se coerentes e correntes para a sociedade brasileira. Então, a formatura e, consequentemente, o conjunto de atos e artefatos (materiais e imateriais) que a integram devem ser compreendidas como:

Um conjunto de atos formalizados, expressivos, portadores de uma dimensão simbólica. O rito é caracterizado é caracterizado por uma configuração espaço-temporal específica, pelo recurso a uma série de objetos, por sistemas de linguagens e comportamentos específicos e por signos emblemáticos cujo sentido codificado constitui um dos bens comuns de um grupo.

Essa é uma definição que: retém critérios morfológicos; insiste na dimensão coletiva, na medida em que o ritual faz sentido para todos que dele compartilham; reconhece que essas manifestações têm um campo específico para marcar rupturas e descontinuidades, momentos críticos (passagem) tanto em tempos individuais quanto em tempos sociais; e prioriza a sua eficácia social.

O ritual faz sentido, visto que ordena a desordem, atribui sentido ao acidental e ao incompreensível, confere aos atores sociais os meios para dominar o mal, o tempo e as relações sociais. Sua essência é misturar o tempo individual e coletivo. Definidos em suas propriedades morfológicas e através de sua eficácia social, os ritos também se caracterizam por ações simbólicas manifestadas por emblemas sensíveis, materiais e corporais.

Enquanto conjuntos fortemente institucionalizados ou efervescentes - quer regulem situações de adesão comum a valores, quer funcionem como reguladores de conflitos interpessoais -, os ritos devem ser considerados sempre como um conjunto de condutas individuais e coletivas relativamente codificadas, com suporte corporal (verbal, gestual e de postural), caráter repetitivo e forte carga simbólica para atores e testemunhas. Tais condutas são fundadas numa adesão mental - de que o ator eventual não tem consciência - a valores relativos de escolhas sociais consideradas importantes e cuja eficácia esperada não advém de uma lógica puramente empírica que se esgotaria na instrumentalidade técnica da ligação causaefeito. Finalmente, o ritual se reconhece como fruto de uma aprendizagem, implicando, por conseguinte a continuidade das gerações, dos grupos etários ou dos grupos sociais dentro dos quais ele se produz.

Através de sua dimensão simbólica, 'o rito é uma linguagem eficaz na medida em que atua sobre a realidade social', decorrendo daí que o rito não se pode fazer de qualquer maneira, precisando apoiar-se em símbolos reconhecidos pela coletividade (SEGALEN, 2002, p. 31-32).

A formatura é uma prática social marcada por rituais que se apoiam em uma miríade de símbolos, dentre os quais atualmente figuram com destaque as placas de formatura, herdeiras dos antigos quadros de formaturas, talhados até a década de 1970, quando foram substituídos pelas placas. As primeiras são utilizadas para demarcar registros, em geral, do término de um curso superior; enquanto os quadros de formatura registravam, indistintamente, 
o encerramento de qualquer fase da educação formal (curso ginasial, comércio, normal, secundário, ensino superior, jardim de infância, etc.), e, em geral feitas por artesãos.

Ao demarcar o rito da formatura, enquanto dimensão de importância ímpar no cotidiano escolar, além de prática social profícua e ressignificada continuamente na sociedade, a proposição deste texto é analisar um dos símbolos que integram a cultura escolar material: quadros de formaturas. Tomamos como fontes históricas vinte e seis (26) quadros produzidos entre as décadas de 1930 a 1970 para celebrar a colação de grau em quatro diferentes cursos: Ginasial, Normal, Comércio (atual curso de Contabilidade) e Jardim de Infância.

Os quadros de formaturas utilizados como fontes de pesquisas e analisados neste texto integram o acervo particular de dois colégios católicos brasileiros dedicados exclusivamente à educação feminina até década de 1970: Colégio Nossa Senhora das Graças ${ }^{4}$ (Parnaíba/Piauí) e Colégio Sagrado Coração de Jesus ${ }^{5}$ (Teresina/Piauí). O conjunto de quadros de formatura do Colégio Nossa Senhora das Graças está exposto em perfeito estado no rol de entrada do prédio principal da escola: para este estudo foram selecionados dezenoves (19) dos mais representativos; enquanto o acervo destes objetos do Colégio Sagrado Coração de Jesus foi removido da sede principal da escola (e a qual não tivemos acesso até o presente momento), sendo possível acessar as imagens de sete (07) quadros de formatura presentes nos arquivos do próprio estabelecimento escolar.

Para analisar e compreender a inserção destes objetos escolares, significados e aportes simbólicos no contexto das solenidades de formatura, da sociedade na qual as estudantes/formandas se imiscuíam, e o próprio estabelecimento que preservou estes artefatos e os mantém expostos em local de destaque para alunos e visitantes, utilizamos os referenciais da História Cultural, a qual oportunizou perceber, além da cultura escolar material, e das memórias inscritas pelos estudantes nesses documentos (os quadros de formaturas são compostos por: esculturas, fotografias, textos, desenhos, etc.), a configuração do contexto sócio-cultural, político e econômico no qual as escolas estavam imersas, bem como as disputas inerentes e existentes nestes cenários.

${ }^{4}$ O Colégio Nossa Senhora das Graças (CNSG) foi fundado em junho 1907 pelas italianas Irmãs Savinianas, na cidade de Parnaíba (PI), à época cidade com maior desenvolvimento econômico do estado. O colégio atendeu exclusivamente mulheres desde a fundação até a década de 1970, quando passou a aceitar matrículas de meninos. Até a presente data a Congregação Saviniana dirigi a instituição de ensino.

${ }^{5}$ O Colégio Sagrado Coração de Jesus (CSCJ) foi fundado em outubro de 1906 pelas italianas Irmãs Savinianas, na cidade de Teresina (PI), capital do estado, ainda com tímido desenvolvimento sócio-econômico e cultural. O colégio foi aberto para atender exclusivamente mulheres a pedido do Bispo da récem criada Diocese do Piauí, Dom Luís Antônio, e assim permaneceu até a década de 1970, quando passou a aceitar matrículas de meninos. Até a presente data a Congregação Saviniana dirige a instituição de ensino. 
Quadros de Formatura: fragmentos de histórias, símbolos de trajetórias, ícones de um projeto pedagógico

Observar e analisar os quadros de formatura (as imagens, as fotografias contidas, os desenhos, os textos escritos, além da arte empregada para talhar e esculpir a madeira) e transformá-los em fontes históricas proporciona a compreensão do cenário social, cultural, histórico e da tessitura de relações nas quais se inscreviam e conviviam os sujeitos sociais no espaço escolar e no espaço social no qual próprio Colégio (co)existia.

Figura 1 - Quadro de formatura-humanistas ${ }^{6}$ de 1941 (Turma Madre Savina)

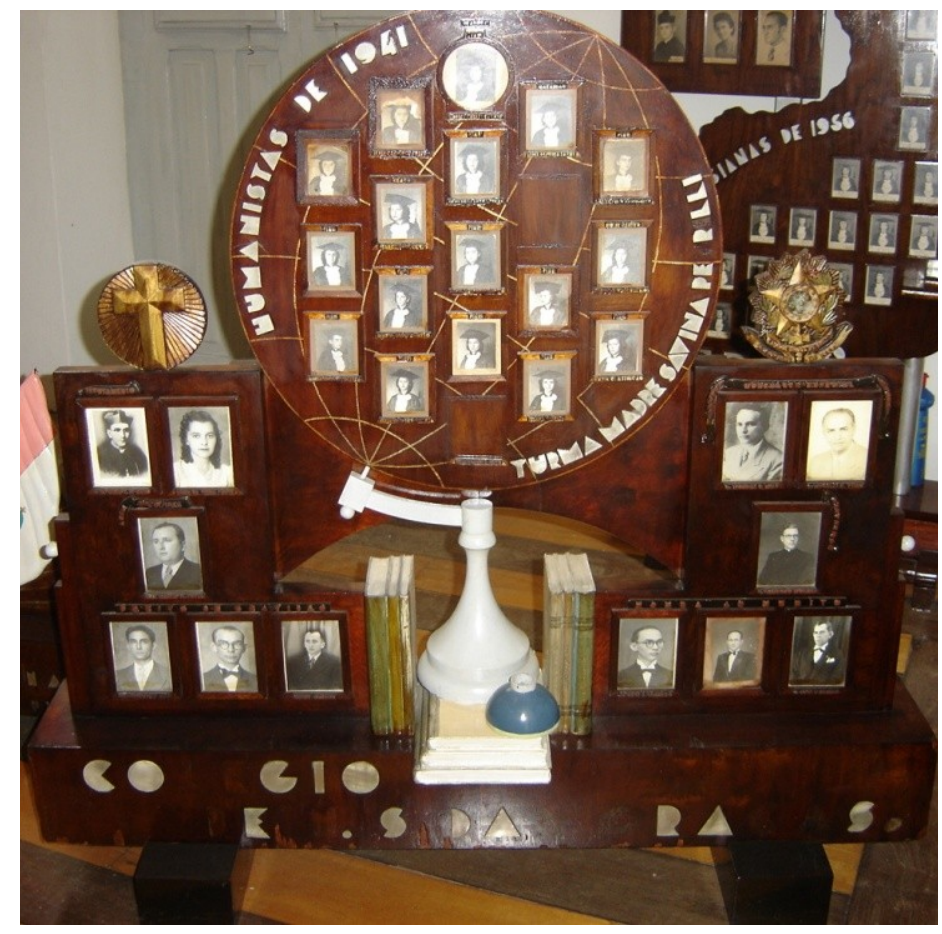

Foto: Márcio Iglésias (jul. 2008) - Acervo Colégio Nossa Senhora das Graças

Os quadros de formatura analisados neste texto pertencem aos acervos dos Colégios Nossa Senhora das Graças (Parnaíba/PI) e Colégio Sagrado Coração de Jesus (Teresina/PI), a escola de Parnaíba manteve estes artefatos históricos expostos no rol de entrada do prédio principal, em lugar de destaque e visível para integrantes do atual corpo discente, docente, funcionários e a todos os visitantes da instituição. E, conforme atesta Werle (2005, p. 09) em local visível,

\footnotetext{
${ }^{6}$ Supõe-se que estas alunas tenham concluído o Curso Ginasial, posto que este curso fosse implantado no Colégio Nossa Senhora das Graças ainda no ano de 1936, antes mesmo de ser ofertado às mulheres da capital do estado (Teresina), situação que foi ocorrer dois anos depois no Colégio Sagrado Coração de Jesus, na Congregação Saviniana da capital.
} 
[...] os quadros de formatura são um indício e um testemunho indelével, da ação institucional e da missão educativa alcançada. Atuam também como exemplo pois fixam uma imagem (sucesso, completude na formação) e, consequentemente expostos, instam aos seus apreciadores a também a alcançarem seus objetivos.

Concebemos quadros de formatura enquanto a materialização de memórias, portanto portadores de um suporte material onde há de se perceber a conjugação, além de investimentos financeiros, social e emocional para a produção da peça quadro de formatura, os elementos simbólicos presentes na estruturação deste artefato prenhe de histórias, trajetórias individuais e coletivas, identidades, que também expõem publicamente o projeto educacional de uma instituição de ensino.

Lembremos que o século XX infundiu tradições de modernidade à sociedade brasileira, e o acesso e difusão da educação formal é um dos pilares desse novo mundo; recorrendo a Le Goff (2003, p. 469) destacamos que:

\begin{abstract}
A tradição é biologicamente tão indispensável à espécie humana como o condicionamento genético o é às sociedades de insetos: a sobrevivência étnica funda-se na rotina, o diálogo que se estabelece suscita o equilíbrio entre rotina e progresso, simbolizando a rotina o capital necessário à sobrevivência do grupo, o progresso, a intervenção das inovações individuais para uma sobrevivência melhorada. A memória é um elemento essencial do que se costuma chamar de identidade, individual ou coletiva, cuja busca é uma das atividades fundamentais dos indivíduos e das sociedades de hoje, na febre e na angústia.
\end{abstract}

Tomando essa perspectiva como ponto de partida para analisar os quadros de formatura dos Colégios Savinianos podemos afirmar que estas relíquias eram para as alunas alçadas ao patamar de formandas por ocasião do encerramento do curso (algumas permaneceriam nos Colégios para continuar os estudos ${ }^{7}$, outras iriam desempenhar a atividade mais honrosa para as mulheres: casar-se e esmerar-se nos cuidados com marido, filhos e lar) uma afirmação de sucesso perante os próprios Colégios, a família, o grupo de colegas da escola, a sociedade e, por fim, sua vinculação com a instituição na qual realizou seus estudos.

Neste ponto de nossas reflexões, é importante frisar as considerações feitas por Werle (2005, p. 10),

\footnotetext{
${ }^{7}$ O Colégio Nossa Senhora das Graças oferecia os cursos: Normal (desde 1934), Comércio (desde 1935), Ginasial (a partir de 1936), Jardim de Infância (a partir de 1960) e Científico (a partir de 1985). Era possível às mulheres que não residiam em Parnaíba frequentar o colégio, pois este ofertava também o regime de internato. $\mathrm{O}$ Colégio Sagrado de Jesus oferecia os cursos: Normal (desde 1931), Comércio (a partir de 1954), Ginasial (1938), Jardim de Infância (a partir de 1938) e Científico (a partir de 1959), Patologia Clínica $-2^{\circ}$ grau profissionalizante (a partir de 1975) e Desenhista de Arquitetura - $2^{\circ}$ grau profissionalizante (a partir de 1975). Era possível as mulheres que não residiam em Teresina frequentar o colégio, pois este ofertava também o regime de internato.
} 
Ter sua fotografia incluída num quadro de formatura reafirma o capital cultural adquirido, o processo de formação vinculado à esta instituição, e não a qualquer outra, e o alcance dos objetivos propostos. Não há como negar, se figurante de um quadro de formatura, a filiação institucional.

Por outro lado, estar incluído num quadro de formatura e ter sua fotografia exposta nos corredores da escola é ter um atestado de que foi e é aceito neste estabelecimento de ensino e por ele está amparado e protegido. A identidade aluno/instituição é reforçada no quadro exposto nos corredores da escola. A notoriedade dos nomes dos alunos, do paraninfo $\mathrm{e}$ professores homenageados, a variedade de lugares de onde os alunos são naturais, confirmam a importância institucional e a abrangência de sua ação formativa, indicando em quantas cidades ela é conhecida.

Assim os quadros de formatura favorecem a que pessoas de várias gerações e com diferentes papéis introjetem a importância da instituição.

No contexto da sociedade piauiense os colégios dirigidos pela Congregação Saviniana desde a fundação (início do século XX) até o presente desfrutam de ampla respeitabilidade na sociedade local e regional, seja pela qualidade do ensino ofertado, seja pela inserção social dos discentes após a conclusão dos estudos, ou mesmo pelas teias de relações sociais e capital social e cultural mobilizado pelos alunos e ex-alunos oriundos destas instituições escolares.

Os quadros de formatura selecionados para análise integram um conjunto maior de peças existentes nos Colégio Nossa Senhora das Graças e Colégio Sagrado Coração de Jesus, contudo estes foram escolhidos pela representatividade quando analisados enquanto fontes históricas.

Quadro 1 - Quadro descritivo dos quadros de formatura do Colégio Nossa Senhora das Graças - Parnaíba (PI)

\begin{tabular}{|c|c|c|l|}
\hline CURSO & ANO & NOME DA TURMA & \multicolumn{1}{c|}{ MATERIAL DO QUADRO } \\
\hline \multirow{5}{*}{ Comércio } & 1939 & Irmã Abelina Ducci & Papel com fotografias e Moldura em madeira. \\
\cline { 2 - 5 } & 1940 & $\begin{array}{c}\text { Irmã Maria da Assunção } \\
\text { Santana }\end{array}$ & Papel com fotografias e Moldura em madeira. \\
\cline { 2 - 5 } & 1942 & Irmã Emília Diniz & Escultura em madeira em formato de coluna. \\
\cline { 2 - 5 } & 1944 & Madre Ester Verita & $\begin{array}{l}\text { Escultura em madeira em formato de barco a } \\
\text { vela, detalhes em metal livros e símbolo da } \\
\text { profissão de guarda livros. }\end{array}$ \\
\cline { 2 - 5 } & 1950 & Catarina de Sena & $\begin{array}{l}\text { Escultura em madeira em formato de página de } \\
\text { livro, com bandeiras de Parnaíba e do Brasil. }\end{array}$ \\
\cline { 2 - 5 } & 1951 & Prof. Darcy F. Araújo & $\begin{array}{l}\text { Papel com fotografias e Moldura em madeira. } \\
\text { Papel com fotografias e Moldura em madeira. }\end{array}$ \\
\hline \multirow{5}{*}{ Ginásio } & 1941 & Madre Savina & $\begin{array}{l}\text { Escultura em madeira em formato de mapa } \\
\text { mundi, cercado de livros, ladeado por pelo } \\
\text { brasão da república (direita) e cruz (esquerda). }\end{array}$ \\
\cline { 2 - 5 } & 1943 & Irmã Severina Rego & $\begin{array}{l}\text { Escultura em madeira em formato de mapa do } \\
\text { Brasil, detalhes em metal: mapa mundi, tinteiro } \\
\text { e pena, lamparina, livro. }\end{array}$ \\
\cline { 2 - 4 } & 1944 & Mons. Roberto Lopes & $\begin{array}{l}\text { Escultura em madeira em formato de coração, } \\
\text { detalhes em metal em formato de: ampulheta, }\end{array}$ \\
\hline
\end{tabular}




\begin{tabular}{|c|c|c|c|}
\hline & & & livros do curso, lamparina e flâmula. \\
\hline & 1950 & Prof. Raul Santos & Papel com fotografias e Moldura em madeira. \\
\hline & 1952 & Prof. Raul Santos & Papel com fotografias e Moldura em madeira. \\
\hline & 1953 & $\begin{array}{c}\text { Prof }^{\mathrm{a}} \text {. Maria da Penha Fonte e } \\
\text { Silva }\end{array}$ & Papel com fotografias e Moldura em madeira. \\
\hline & 1956 & Dr. Sebastião Castelo Branco & $\begin{array}{l}\text { Escultura em madeira em formato de mapa do } \\
\text { Piauí. }\end{array}$ \\
\hline \multirow[t]{4}{*}{ Normal } & 1957 & Prof ${ }^{\mathrm{a}}$. Clea Araújo F. Lima & Escultura em madeira em formato de âncora. \\
\hline & 1962 & Prof. José L. Couto & $\begin{array}{l}\text { Escultura em madeira em formato de estrela } \\
\text { cadente. }\end{array}$ \\
\hline & 1960 & Prof $^{\mathrm{a}}$ Maria Christina & Papel com fotografias e Moldura em madeira. \\
\hline & 1970 & Irmã Eugênia de Oliveira & Escultura em madeira em formato de quadro. \\
\hline \begin{tabular}{|c|} 
Sem \\
identificação \\
do Curso
\end{tabular} & 1949 & Clea Furtado Araújo & $\begin{array}{l}\text { Escultura em madeira em formato do brasão } \\
\text { Colégio Nossa Senhora das Graças, detalhes em } \\
\text { metal lamparina, livro, ampulheta, globo, } \\
\text { entalhe insígnia de Maria Santíssima. }\end{array}$ \\
\hline
\end{tabular}

Fonte: Elaborado pela autora

Os quadros de formatura denotam diferentes investimentos realizados pelas concludentes dos diversos cursos existentes em uma mesma instituição - ainda que todas sejam detentoras de alto padrão socioeconômico -; observando os produzidos pelo Curso de Comércio percebemos que no intervalo de duas décadas somente duas turmas produziram esculturas para demarcar o encerramento de seu curso no Colégio, enquanto este era o tipo de quadro de formatura adotado pela maioria das turmas concludentes dos cursos de Ginásio e Normal, no Colégio Nossa Senhora das Graças.

No entanto, quando observamos o conjunto dos quadros de formatura do Colégio do Colégio Sagrado Coração de Jesus, encontramos somente uma escultura de madeira produzida pela Turma de 1942 do Curso Normal; contraditoriamente, a prática estabelecida pelas turmas anteriores e posteriores utilizaram a composição do conjunto: desenho/ilustração e fotografia, moldura de madeira e vidro para os quadros de formatura.

Quadro 2 - Quadro descritivo dos quadros de formatura do Colégio Sagrado Coração de Jesus - Teresina (PI)

\begin{tabular}{|l|c|c|l|}
\hline CURSO & ANO & NOME DA TURMA & \multicolumn{3}{|c|}{ MATERIAL DO QUADRO } \\
\hline Normal & 1936 & Professoras de 1936 & $\begin{array}{l}\text { Papel com fotografias e Moldura em } \\
\text { madeira. }\end{array}$ \\
\cline { 2 - 5 } & \multirow{2}{*}{1942} & Professoras de 1942 & $\begin{array}{l}\text { Escultura em madeira em formato do mapa } \\
\text { do estado do Piauí corado pelo brasão } \\
\text { nacional, destacando os limites dos 48 } \\
\text { municípios existentes no estado naquele ano. }\end{array}$ \\
\hline \multirow{3}{*}{ Ginásio } & 1935 & Diplomadas de 1935 & $\begin{array}{l}\text { lapel com fotografias e Moldura em } \\
\text { madeira. }\end{array}$ \\
\cline { 2 - 6 } & 1939 & Diplomadas de 1939 & $\begin{array}{l}\text { lapel com fotografias e Moldura em } \\
\text { madeira. }\end{array}$ \\
\cline { 2 - 6 } & 1942 & Concludentes de 1942 & Papel com fotografias e Moldura em \\
\hline
\end{tabular}




\begin{tabular}{|c|c|c|llll|}
\hline & & & madeira. & & & \\
\hline $\begin{array}{c}\text { Jardim } \\
\text { de } \\
\text { Infância }\end{array}$ & 1937 & $\begin{array}{c}\text { Jardim de Infância - Alunos } \\
\text { de 1937 }\end{array}$ & $\begin{array}{l}\text { Papel com fotografias e } \\
\text { madeira. }\end{array}$ & $\begin{array}{l}\text { Moldura em } \\
\text { Turma do Congresso }\end{array}$ & $\begin{array}{l}\text { Papel com fotografias e } \\
\text { madeira. }\end{array}$ & Moldura em \\
\hline
\end{tabular}

Fonte: Elaborado pela autora

Figura 2 - Quadro de formatura - Jardim de Infância de $1960^{8}$ (Turma do Congresso)

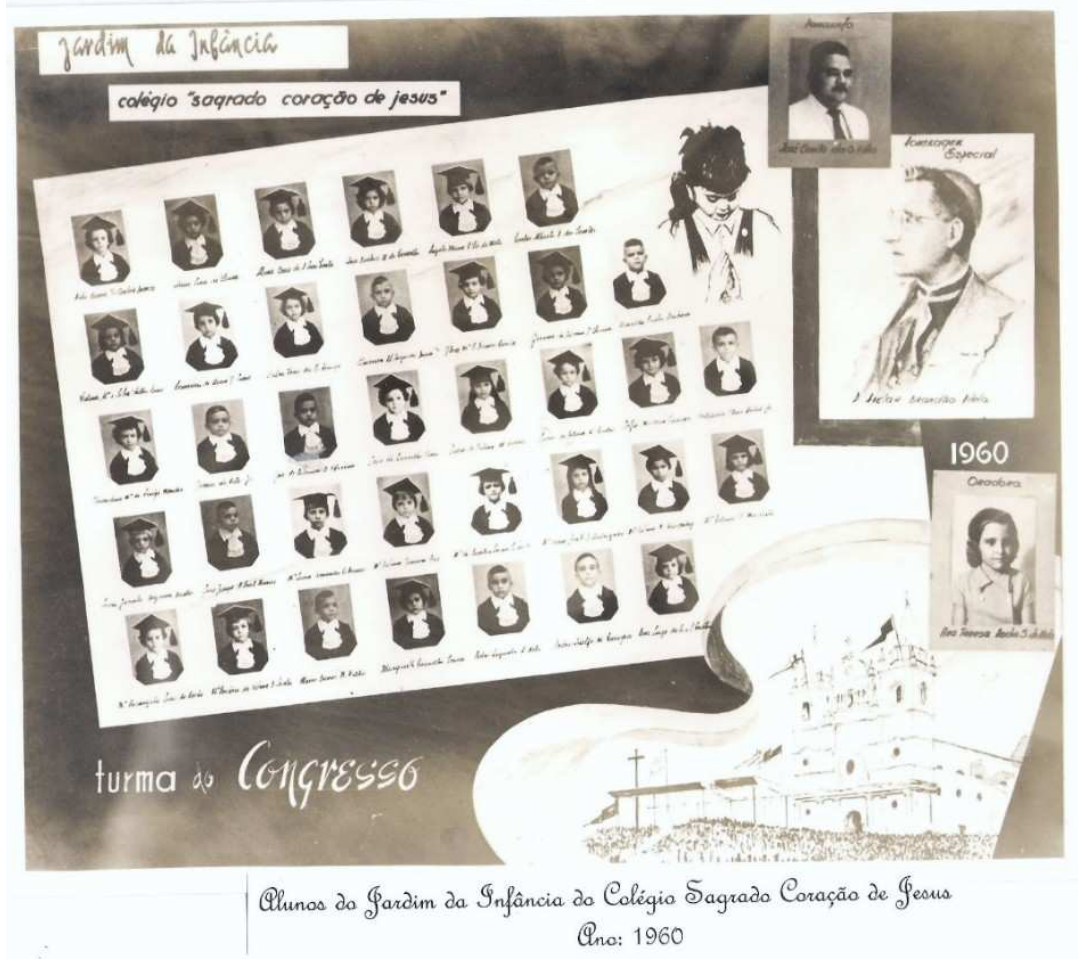

Foto: Acervo Colégio Sagrado Coração de Jesus

Elemento diferenciador entre as duas instituições savinianas quanto à distinção das formandas é a forma de nomear as turmas concludentes. Enquanto na escola parnaibana, em geral, se utilizou deste como recurso a mais para "capitalizar relações para as formandas" recorrendo para homenagens a personalidades locais e estaduais, "batizando" as turmas com o nome destas pessoas e os trazendo para o interior do espaço escolar para conhecer a "excelente formação provida pelo Colégio às moças da sociedade"; a escola da capital deu preferência para demarcar e reforçar a qualidade do ensino do Colégio nos quadros de formatura, autonomeando as turmas com o nome do próprio Curso que concluíam seguido do ano da conclusão. A exceção foi a Turma do ano de 1960 do Jardim de Infância, que recebeu o nome de Turma do Congresso.

\footnotetext{
${ }^{8}$ A fotografia impressa no lado direito inferior do quadro de formatura da Turma do Congresso do Jardim de Infância - 1960 foi distribuída por Dom Avelar Brandão Vilela como lembrança de participação no I Congresso Eucarístico (1960) a todas as alunas e alunos dos Colégios Católicos.
} 
Naquele ano aconteceu em Teresina o I Congresso Eucarístico, no período de 26 a 30 de outubro de 1960, durante a gestão episcopal do arcebispo Dom Avelar (governou a Arquidiocese do Piauí entre 1955 e 1971). O evento também celebrou as Bodas de Prata (25 anos) de Sacerdócio de Dom Avelar Brandão Vilela. Todos os alunos dos Colégios Confessionais Católicos de Teresina (masculinos e femininos) participaram do evento, incluindo as alunas do Colégio Saviniano.

Figura 3 - Quadro de formatura-curso normal de 1960 (Turma Prof ${ }^{a}$. Maria Christin)

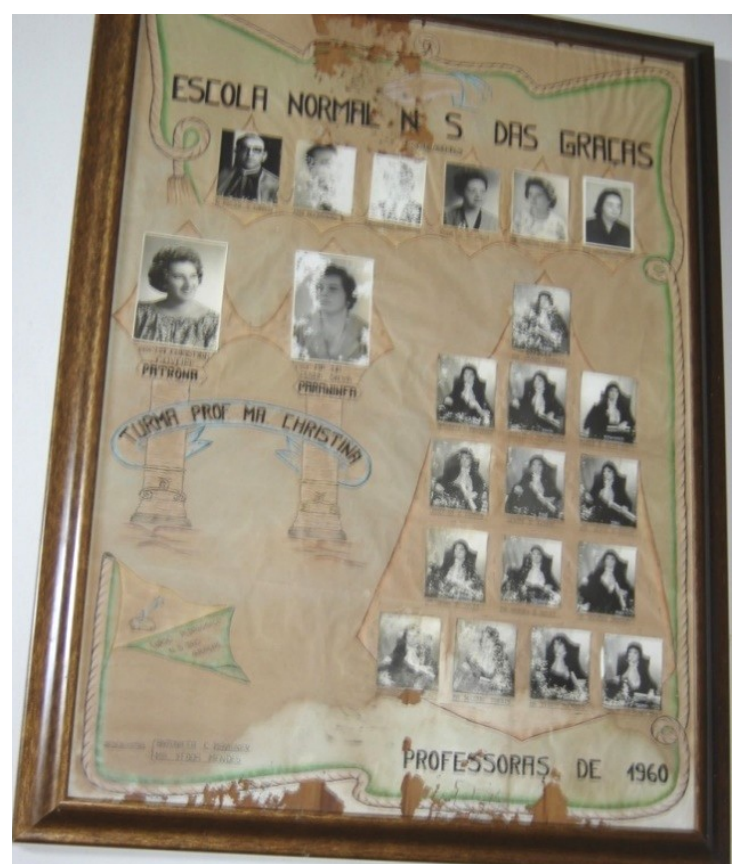

Foto: Márcio Iglésias (jul. 2008) - Acervo Colégio Nossa Senhora das Graças

Outro aspecto que não podemos detectar nos quadros de formatura, seja pelo desgaste promovido pelo tempo, seja pela intencionalidade dos produtores, foi a autoria das peças (esculturas, desenhos, fotografias, molduras etc.) que integram estes artefatos que analisamos. Excetuando-se pelo quadro da Turma de 1960 do Curso Normal, no qual os desenhos que ilustram o quadro foram feitos à mão por Antonieta C. Mavignier e Maria Yedda Mendes (ambas formandas nesta turma), que assinam como desenhistas no canto inferior esquerdo da tela.

Esta impossibilidade de não reconhecer e/ou identificar a autoria das peças de certo modo é impactante, posto que a circulação de quadro de formaturas no Brasil e na cidade de Parnaíba é grande, tanto de peças em tamanho maior - aquela destinada a ser afixada no espaço da instituição de ensino - quanto de peças em tamanho menor - aquelas destinadas a 
serem guardadas como recordação pelo indivíduo que conclui o curso ou presenteada por este a alguém, em geral, familiar ou homenageados pela turma. Encontramos um exemplar destes quadros de formaturas (de mesa) entre os existentes no Colégio Nossa Senhora das Graças.

Figura 4 - Quadro de formatura - professorandas de 1970 (Turma Irmã Eugênia de Oliveira)

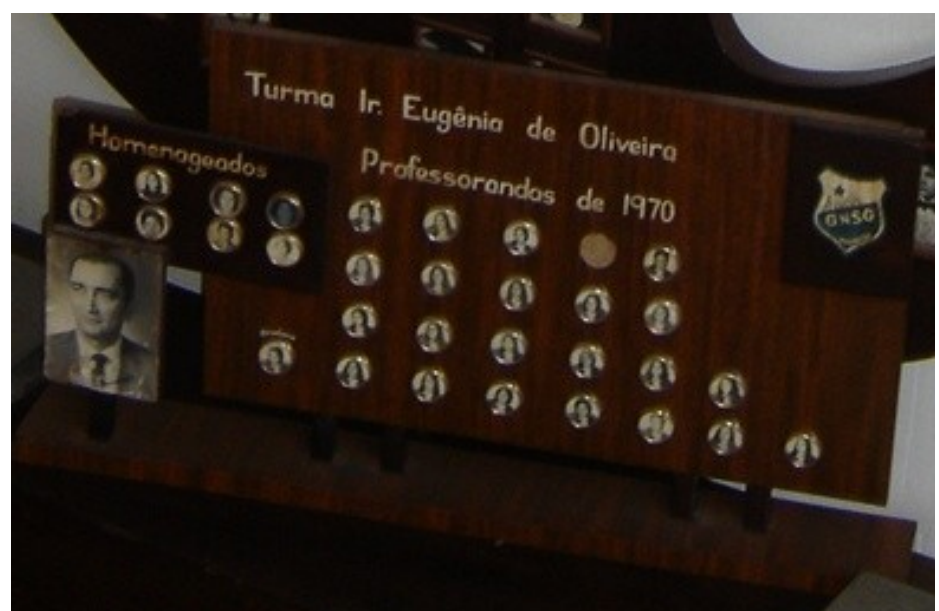

Foto: Márcio Iglésias (jul. 2008) - Acervo Colégio Nossa Senhora das Graças

Um elemento presente em todos os quadros de formaturas analisados dos colégios savianianos é a interrelação entre religiosidade e civismo, demonstrando os elos vigentes entre Igreja e Estado no Brasil em todas as esferas, e os quadros publicizam de forma indelével esta articulação. Por exemplo, o quadro de Formatura da Turma de Comércio de 1940 tem ao centro a imagem de Nossa Senhora das Graças e em destaque do lado esquerdo em tamanho maior que todas as demais fotografias do quadro o retrato do presidente Getúlio Vargas; enquanto o quadro de formatura da Turma de Ginásio de 1943 é uma escultura em formato de mapa do Brasil e tem como um dos homenageados Dom Severino Vieira de Mello (bispo do Piauí), com os seguintes dizeres "com o pleito de filial devotamento".

Os quadros de formatura nos revelam as interligações e tensões existentes na teia social na qual os colégios se imiscuíam: verificamos a partir das representações inscritas nestes as flutuações e intercorrências da economia local e nacional no cotidiano das alunas formandas, especialmente quando se tratava do curso de comércio. Por exemplo, a Turma de 1943 fez uma Escultura em madeira em formato de barco a vela, com detalhes em metal de livros e símbolo da profissão de guarda livros, e outras turmas do Curso de Comércio inseriam em seus quadros barcos, trens e aviões, expondo Parnaíba enquanto entreposto comercial e cidade exportadora, ou seja, atividades econômicas nas quais as famílias das 
alunas estavam envolvidas, e de onde certamente advinha parte da renda que as mantinha no Colégio. Isto nos mostra a busca das formandas por tecer relações no espaço externo ao colégio que facilitasse acesso ao mercado de trabalho, além de homenagear suas famílias e professores do colégio, através das escolhas dos paraninfos, padrinhos, homenageados etc.

Consideramos que os quadros de formatura do início do século XX mantêm relação direta com as atuais Placas de Formatura, por cumprirem a mesma função, ou seja, demarcar a passagem dos formandos (então ex-aluno) no espaço escolar, e informar aos discentes que virão que aqueles galgaram a conclusão o curso e, provavelmente, também, sucesso posterior no mundo externo à instituição de ensino. Os quadros distinguem-se das Placas pela imponência e requinte dos primeiros, tanto em tamanho quanto nos materiais utilizados para a confecção dos mesmos. Para exemplificar, as esculturas em madeiras consideradas nobres eram talhadas em imbuia, carvalho, cedro e possuíam em média altura entre $1 \mathrm{~m} 50 \mathrm{~cm}$ e $2 \mathrm{~m}$ e largura de $1 \mathrm{~m} 50 \mathrm{~cm}$, ricamente adornadas com detalhes em metal, por vezes, em cobre ou bronze.

Percebemos o trabalho de dedicação e detalhismo do artesão ao talhar a peça que se tornaria um quadro de formatura. Tomemos como exemplo o quadro de formatura da Turma de 1942 do Curso Normal do Colégio de Teresina, que foi esculpido no formato do mapa do estado do Piauí com todos os limites territoriais dos quarenta e oito (48) municípios que até então o integravam. As fotografias das formandas foram inseridas dentro destes "limites dos municípios", levando o observador a acreditar que as mesmas estão posicionadas em conformidade com o local de sua naturalidade, posto que há espaços correspondentes a determinados municípios em que há mais de uma foto e outros que foram deixados vazios. A escultura em madeira do mapa é coroada pelo brasão da República fundido em metal, o que denota a superioridade do poder da nação em relação ao poder local. 
Figura 5 - Quadro de formatura- Colégio Sagrado Coração de Jesus (Turma Professoras de 1942)

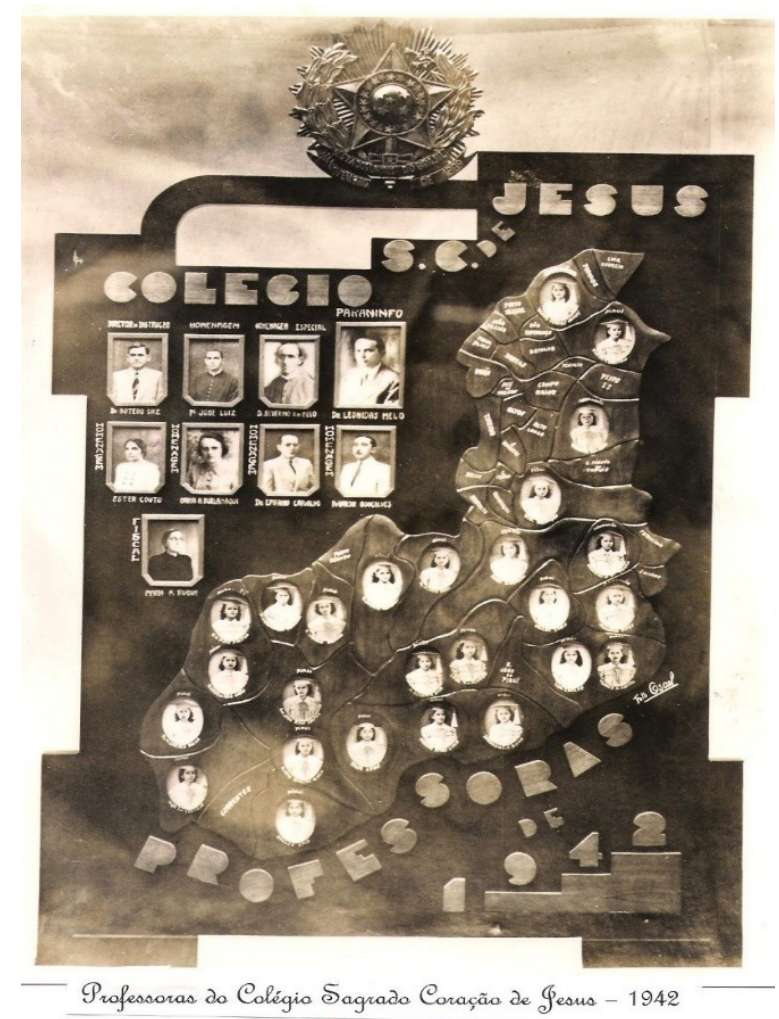

Foto: Acervo Colégio Sagrado Coração de Jesus

O estudo dos quadros de formatura revela um arcabouço de informações sobre a cultura e realidade escolares entremeados pelos ritos usuais das formaturas. Contudo, é necessário ao analista articular, além dos referenciais da História e História da Educação, elementos da economia, sociologia, antropologia - dentre outras áreas - para compreender a extensão dos significados e aportes simbólicos emanados a partir dos quadros, mesmo quando os sujeitos ali representados não estão presentes fisicamente e nem seus nomes são recordados pelos viventes. Estar inserido em um quadro de formatura assegura uma notoriedade singular e admiração ímpar, despertando naqueles sujeitos que agora estão a circular no espaço escolar - mesmo nos que não partilham efetivamente daquela cultura escolar - admiração, com o anseio de atingir as conquistas e méritos possibilitadores de "ser dignos de estar em um quadro de formatura". Precisamos buscar amplificar a compreensão histórico-social e cultural sobre como estas peças decorativas e ritualísticas mantêm a força do simbolismo. 


\section{Considerações finais}

Ao analisar os quadros de formatura nos é possibilitado compreender outras interrelações e conexões consolidadas entre o espaço escolar e a sociedade que o comporta, delineia, molda e é moldada por ele, permitindo, assim, desnudar uma diversidade de amplificações do campo da História da Educação, especificamente da cultura escolar material.

O estudo dos Quadros de Formatura, embora instigante, ainda é incipiente, está subjacente a outros objetos da cultura escolar material, seja porque poucos exemplares destes artefatos foram preservados nas e pelas instituições escolares, seja porque os seus sucessores - as placas de formatura - fazem parte de nossa rotina escolar, e, ainda não voltamos o olhar histórico para estas fontes históricas que ao mesmo tempo se desdobram e/ou congregam três outros tipos de fontes (imagética, arte, escrita).

Há uma escassez de bibliografia abordando a temática de quadros de formaturas, tanto no que se refere à análise destas fontes históricas existentes em instituições de educação básica quanto de ensino superior. Aqui é importante salientar que estes artefatos são importantes elementos para revelar as práticas pedagógicas e os projetos educacionais das instituições, ou seja, reveladores da cultura escolar.

Certamente adentrar no simbolismo dos rituais de colação de grau é revolver turbilhões de memórias vividas, expectativas não realizadas e projetos gestados não realizados; observar quadro de formaturas é também imaginar que sonhos foram realizados ainda que por frações de segundos no mágico instante das solenidades de passagens, no calor das emoções despertas; olhar as fotografias de séculos anteriores é reviver as lembranças que não são nossas, mas poderiam ter sido e são, porque a formatura, a conclusão do curso, integra parte da nossa realidade social brasileira, constitui-se ainda em um rito de passagem que de uma forma ou de outra todos nós brasileiros desejamos celebrar.

\section{REFERÊNCIAS}

BENCOSTA, M. L. (Org). Culturas escolares, saberes e prática educativas: intinerários históricos. São Paulo, SP: Cortez, 2007

LE GOFF, J. História e memória. 5. ed. Campinas, SP: Ed. UNICAMP. 2003.

SEGALEN, M. Ritos e rituais contemporâneos. Rio de Janeiro, RJ: FGV Editora, 2002. 
WERLE, F. O. C. Ancorando quadros de formatura na história institucional. In: REUNIÃO ANUAL DA ANPED, 28., 2004, Caxambu. Anais [...]. Caxambu, MG: ANPED, 2005.

Disponível em: https://www.anped.org.br/sites/default/files/gt02-322-int_ok.pdf. Acesso em: 20 fev. 2021.

\section{Como referenciar este artigo}

SILVA, S. M. A. Molduras para fragmentos da história do século XX: Quadros de formaturas e memórias escolares de colégios católicos brasileiros no século XX. Revista IberoAmericana de Estudos em Educação, Araraquara, v. 16, n. esp.3, p. 1439-1454, jun. 2021. e-ISSN: 1982-5587. DOI: https://doi.org/10.21723/riaee.v16iesp.3.15291

Submissão em: 05/02/2021

Revisões requeridas em: 30/03/2021

Aprovado em: $12 / 05 / 2021$

Publicado em: 01/06/2021 